\title{
Evaluation of Erastin as a Therapeutic Agent Under Hypoxic Conditions in Pancreatic Cancer Cells
}

\author{
SATOSHI OWADA, HITOSHI ENDO, YUKARI SHIDA, TAKAAKI KINOUE, \\ HIROYUKI FURUYA and MASAYUKI TATEMICHI
}

Department of Preventive Medicine, Tokai University School of Medicine, Isehara, Japan

\begin{abstract}
Background/Aim: In pancreatic cancer tissues, hypoxic areas exist due to poor blood flow. Attenuation of the pharmacological efficacy of existing anticancer drugs in these hypoxic areas necessitates the search for novel anticancer compounds. We aimed to determine whether erastin exhibits anticancer effects in a hypoxic environment. Materials and Methods: Pancreatic cancer cell lines were subjected to cobalt chloride, a hypoxia-mimicking agent. Cell viability assay, measurement of reactive oxygen species, and western blotting analysis were conducted to investigate the efficacy of erastin under hypoxic environments. Results: Erastin exhibited remarkable cytotoxicity and induced apoptosis under hypoxic conditions. Furthermore, erastin triggered the intracellular accumulation of reactive oxygen species in a hypoxic environment. Subsequent treatment with $N$-acetylcysteine, an antioxidant, markedly attenuated cytotoxicity, and apoptosis. Conclusion: Erastin induces cell death by accumulation of intracellular reactive oxygen species and inducing apoptosis under hypoxic conditions, proving its potential for further development as a novel anticancer compound.
\end{abstract}

Pancreatic cancer is known to have a poor prognosis. It is estimated that by 2030 , the number of deaths from pancreatic cancer will have further increased, making it the second leading cause of mortality worldwide $(1,2)$. Early detection of pancreatic cancer is difficult. Furthermore, patients with newly diagnosed pancreatic cancer often develop distant metastasis or local recurrence. Thus, many patients are treated with systemic chemotherapy or radiotherapy rather

This article is freely accessible online.

Correspondence to: Satoshi Owada, Ph.D., Department of Preventive Medicine, Tokai University School of Medicine, 143 Shimokasuya, Isehara, Kanagawa 259-1193, Japan. Tel: +81 463931121 (ext. 2623), e-mail: sowada@tsc.u-tokai.ac.jp

Key Words: Apoptosis, hypoxia, erastin, reactive oxygen species, pancreatic cancer. than surgery. The use of chemotherapeutic agents such as single-agent gemcitabine, TS-1 (tegafur, gimeracil, and oteracil potassium), and FOLFILINOX (fluorouracil, leucovorin, irinotecan, and oxaliplatin) has resulted in a 5year survival rate of $\leq 10 \%$ (3).

Pancreatic cancer tissues develop immature and heterogeneous vascular networks owing to active cellular proliferation (4). Oxygen and nutrition are supplied to cancer tissues through the bloodstream; thus, pancreatic cancer tissues are exposed to a hypoxic environment (5). Indeed, the mean partial pressure of oxygen of pancreatic cancer tissues was reported to be $0.4 \%$, which is significantly lower than that of normal pancreatic tissues (6.8\%) (6).

The hypoxic environment of tumour tissues markedly attenuates the pharmacological efficacy of anticancer agents (7-10). Therefore, there is an urgent for novel anticancer compounds that specifically target the hypoxic environment of pancreatic cancer tissues.

Previously, we identified mechanisms that stimulated cytotoxicity in hypoxic environments. We reported that it was possible to induce hypoxia-selective cytotoxicity by inhibiting autophagy and nicotinamide adenine dinucleotide phosphate oxidase 4 (NOX4) (11-13). Specifically, inhibition of NOX4 or autophagy led to the excessive accumulation of reactive oxygen species (ROS) in cells, which subsequently induced hypoxic environment-selective cell death. Therefore, analysing specific indicators associated with intracellular accumulation of ROS under hypoxic conditions may be an effective strategy for identifying the efficacy of novel anticancer compounds.

Erastin, a ferroptosis inducer, is a potent agent for pancreatic cancer treatment (14). Erastin-induced cytotoxicity is caused by the accumulation of intracellular ROS (15-17). Therefore, we hypothesised that this compound would be able to induce cytotoxicity even in hypoxic environments. Proving that erastin exerts anticancer effects in both normal and hypoxic environments may lead to the development of a novel chemotherapeutic strategy against pancreatic cancer. However, to our knowledge, no previous studies have examined the effect of erastin on cell death under hypoxic conditions. 
In this study, we aimed to investigate the effect of erastin on cell death in a hypoxic environment and explore its potential as a novel drug against pancreatic cancer.

\section{Materials and Methods}

Cell lines and culture conditions. The human pancreatic cancer cell lines PANC-1 and BxPC-3 were obtained from the European Collection of Cell Cultures (Salisbury, UK). The human pancreatic cancer cell line MIA PaCa-2 was obtained from the Japanese Collection of Research Bioresources (Osaka, Japan). All cell lines were cultured in Dulbecco's modified Eagle's medium supplemented with fetal bovine serum to a final concentration of $10 \%(\mathrm{v} / \mathrm{v}), 50 \mu \mathrm{g} / \mathrm{ml}$ streptomycin, $50 \mathrm{U} / \mathrm{ml}$ penicillin, and nonessential amino acids (Gibco BRL, Paisley, UK).

Reagents. Materials were obtained from the following sources: Erastin from Cayman Chemical (Ann Arbor, MI, USA); hypoxiainducible factor 1 alpha (HIF1 $\alpha$ ) antibody from GeneTex (Irvine, CA, USA); actin antibody and 3'-O-acetyl-6'-O-pentafluorobenzenesulfonyl-2', 7'-difluorofluorescein (BES- $\mathrm{H}_{2} \mathrm{O}_{2}$-Ac) from Wako Pure Chemical Industries (Osaka, Japan); Hoechst 33342 from Calbiochem-Merck (Darmstadt, Germany); Dulbecco's modified Eagle's medium, $N$-acetylcysteine (NAC), ferrostatin-1, and cobalt chloride $\left(\mathrm{CoCl}_{2}\right)$ from Sigma-Aldrich (St. Louis, MO, USA); benzyloxycarbonyl-Val-Ala-Asp (OMe) fluoromethylketone (Z-VAD-FMK) and poly (ADP-ribose) polymerase (PARP) antibody from Cell Signaling Technologies (Beverly, MA, USA); necrostatin1, a necroptosis inhibitor, from Abcam (Cambridge, UK); CellROX Green Reagent from Life Technologies (Paisley, UK).

$\mathrm{CoCl}_{2}$, NAC and Hoechst 33342 were dissolved in phosphatebuffered saline (PBS). Erastin, ferrostatin-1, Z-VAD-FMK and necrostatin-1 were dissolved in dimethyl sulfoxide (DMSO). PBS or DMSO was used as a vehicle control.

Establishment of hypoxic conditions. In all experiments, cells were seeded at $60-70 \%$ confluence for $24 \mathrm{~h}$, and then were exposed to erastin in the absence (vehicle control PBS) or presence of 300 $\mu \mathrm{M} \mathrm{CoCl} 2$.

Cell viability assay. The cells were seeded in 96-well plates at a density of $3 \times 10^{3}$ cells/well. After treatment with or without $\mathrm{CoCl}_{2}$, the cells were treated for $48 \mathrm{~h}$ with the erastin $(2$ or $20 \mu \mathrm{M})$ alone or in combination with the following compounds: NAC $(0.5 \mathrm{mM})$, ferrostatin-1 $(10 \mu \mathrm{M})$, necrostatin-1 $(20 \mu \mathrm{M})$, or Z-VAD-FMK (50 $\mu \mathrm{M})$. Cytotoxicity was evaluated using a Cell Counting Kit-8 (CCK8; Dojindo, Kumamoto, Japan). Cell viability values were normalised to those of the vehicle control.

Western blotting analysis. Protein extraction and western blotting analysis were performed as previously described $(18,19)$. Immunoblotting was performed using antibodies to HIF1 $\alpha$ $(1: 1,000)$, PARP $(1: 1,000)$, and actin $(1: 10,000)$.

ROS detection assays. Confocal microscopy: Cellular ROS accumulation in BxPC-3 cells was detected with BES- $\mathrm{H}_{2} \mathrm{O}_{2}-\mathrm{Ac}$ and CellROX per the manufacturer's instructions. Briefly, BxPC- 3 cells were prepared in $35 \mathrm{~mm}$ glass-bottom $\mu$-Dish (ibidi $\mathrm{GmbH}$, Munich, Germany). BxPC-3 cells were treated with different concentrations of erastin in the absence or presence of $300 \mu \mathrm{M} \mathrm{CoCl}_{2}$ for $24 \mathrm{~h}$. BES- $\mathrm{H}_{2} \mathrm{O}_{2}$-Ac or CellROX was then added to the cell culture media at a final concentration of $5 \mu \mathrm{M}$. Finally, BxPC-3 cells were incubated for $45 \mathrm{~min}$ at $37^{\circ} \mathrm{C}$. The samples were analysed using confocal microscopy (LSM 700; Zeiss, Jena, Germany).

Fluorescence plate reader: $\mathrm{BxPC}-3$ cells were seeded at a density of $3 \times 10^{3}$ cells/well in 96-well plates (Sumitomo Bakelite, Tokyo, Japan). BxPC-3 cells were treated with different concentrations of erastin in the absence or presence of $300 \mu \mathrm{M} \mathrm{CoCl}_{2}$ for $24 \mathrm{~h}$, and then $5 \mu \mathrm{M}$ BES- $\mathrm{H}_{2} \mathrm{O}_{2}$-Ac was added to the wells. BES- $\mathrm{H}_{2} \mathrm{O}_{2}-\mathrm{Ac}$ fluorescence was measured after $30 \mathrm{~min}$ using a fluorescence plate reader $($ excitation $=485 \mathrm{~nm}$, emission $=520 \mathrm{~nm}$ ). The fluorescence values obtained from each well were normalised to the cell viability results of the same sample well by CCK- 8 assay.

Statistical analysis. Each experiment was repeated at least three times. Data are expressed as the mean \pm standard deviation. Comparisons between multiple groups were performed by one-way analysis of variance followed by Scheffe post hoc test or two-way analysis of variance followed by Scheffe post hoc test. Differences with values of $p<0.05$ were considered statistically significant.

\section{Results}

Cytotoxicity of erastin under hypoxic conditions. $\mathrm{CoCl}_{2}$ was used to mimic a hypoxic environment (20). Intracellular accumulation of HIF1 $\alpha$, a hypoxia marker, was observed upon $\mathrm{CoCl}_{2}$ treatment of BxPC-3 cells (Figure 1A). We subsequently examined the effects of erastin on cell survival. Remarkable cytotoxicity was observed upon treatment with $20 \mu \mathrm{M}$ erastin under normal conditions, which was consistent with the results of a previous study (16). Under hypoxic conditions, considerable cytotoxicity was observed upon administration of $2 \mu \mathrm{M}$ erastin, which was maintained at a concentration of 20 $\mu \mathrm{M}$ (Figure 1B). Additionally, we analysed the responses of PANC-1 and MIA PaCa-2 cells to investigate whether this was a common phenomenon in pancreatic cancer cell lines and found that erastin induced marked cytotoxicity under hypoxic conditions in these cells (Figure 1C-F). These results strongly suggest that erastin may be an effective anticancer compound, even under hypoxic conditions.

Effect of ROS on the cytotoxicity of erastin under hypoxic conditions. Next, we explored the mechanism of erastininduced cytotoxicity in hypoxic environments. Under normoxic conditions, the cytotoxicity of erastin is caused by ferroptosis, which is mediated by lipid ROS accumulation $(21,22)$. Therefore, we investigated whether erastin leads to intracellular ROS accumulation in a hypoxic environment. We used the CellROX (23) and BES- $\mathrm{H}_{2} \mathrm{O}_{2}$-Ac (24) probes to detect ROS. As previously reported, under normoxic conditions, marked intracellular accumulation of ROS was observed upon treatment with $20 \mu \mathrm{M}$ erastin, consequently inducing cell death. Marked intracellular accumulation of ROS and consequent cell death was also observed under hypoxic conditions upon 
A

BxPC-3

$\mathrm{CoCl}_{2}(300 \mu \mathrm{M}) \quad-+$

HIF1 $1 \alpha$

Actin

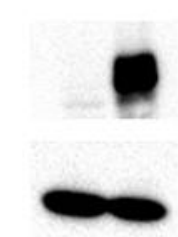

C

PANC-1

$\mathrm{CoCl}_{2}(300 \mu \mathrm{M}) \quad-+$

HIF1a

Actin
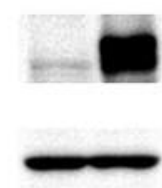

E

MIA PaCa-2

$\mathrm{CoCl}_{2}(300 \mu \mathrm{M}) \quad-+$

HIF1a

Actin
B

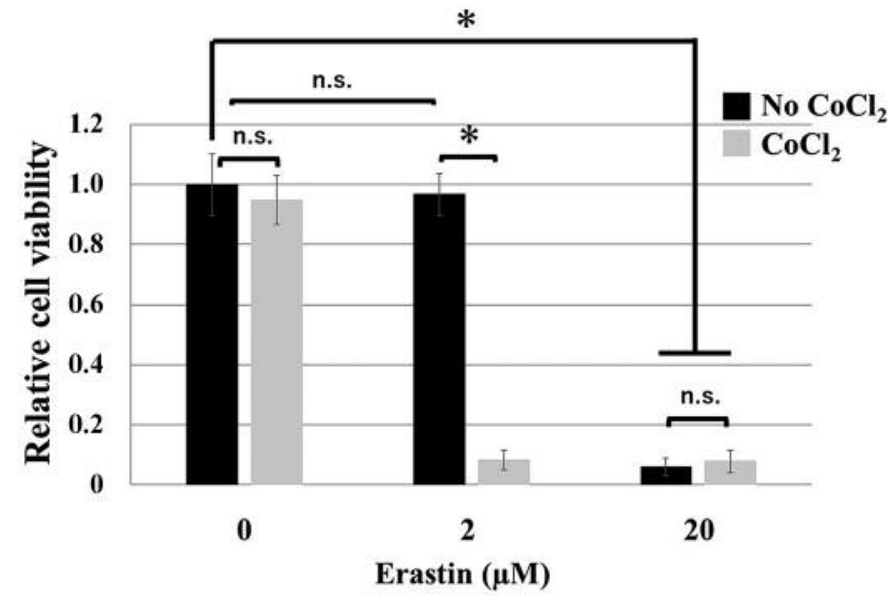

D
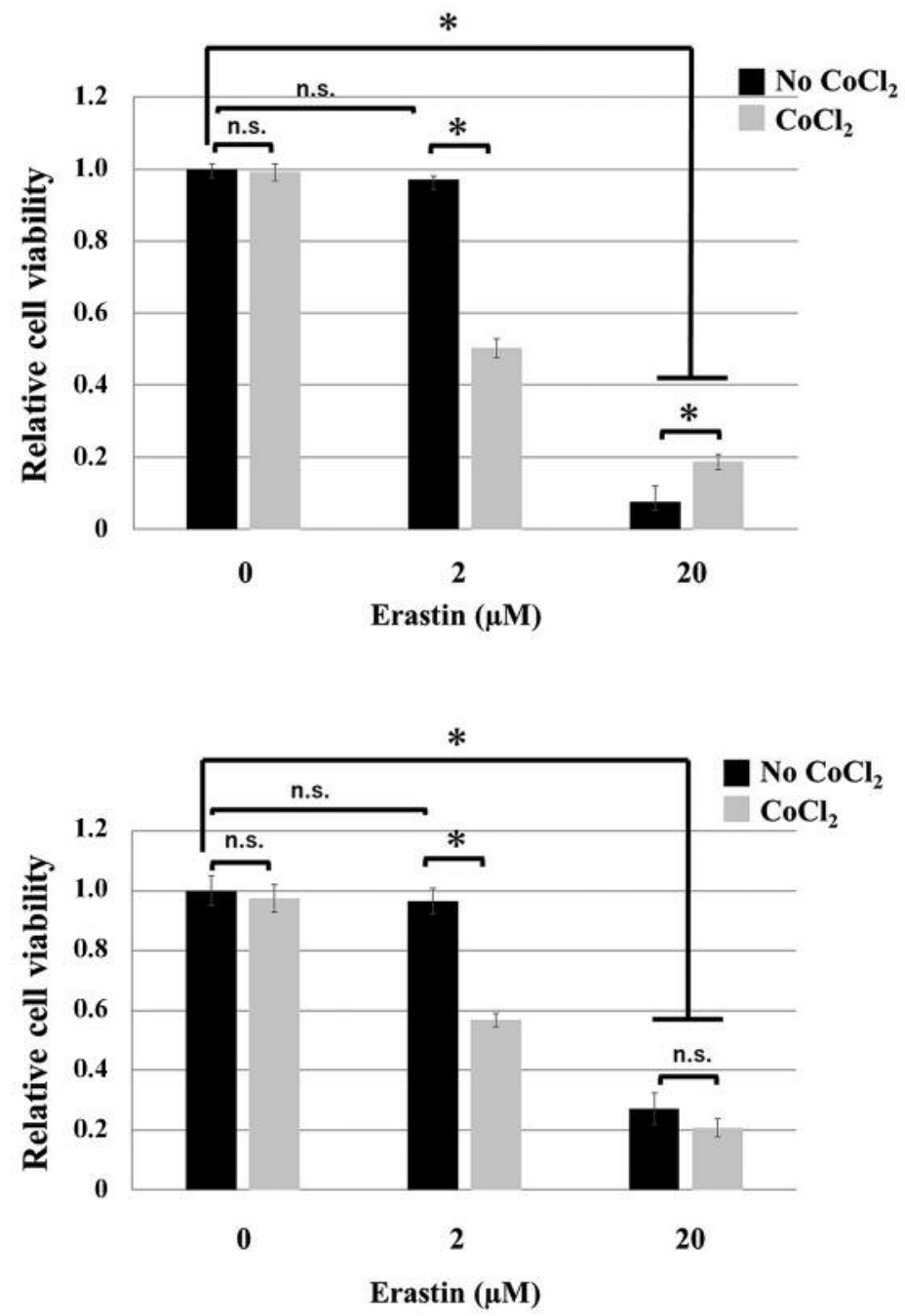

Figure 1. Erastin-induced cytotoxicity under hypoxic conditions. A: BxPC-3 pancreatic cancer cells were exposed to $300 \mu \mathrm{M} \mathrm{CoCl} \mathrm{f}_{2}$ for $48 \mathrm{~h}$, followed by the western blotting analysis of hypoxia-inducible factor 1 alpha (HIF1 $\alpha$ ) and actin. B: BxPC-3 cells were subjected to different concentrations of erastin for $48 \mathrm{~h}$ in the absence or presence of $300 \mu \mathrm{M} \mathrm{CoCl}$ then Cell Counting Kit-8 analysis was used to measure BxPC-3 cell viability. Corresponding HIF $1 \alpha$ and protein expression and viability results for PANC-1 $(C, D)$ and MIA PaCa-2 (E, F) pancreatic cancer cells. * Significantly different at $p<0.05$; n.s.: not significantly different. 


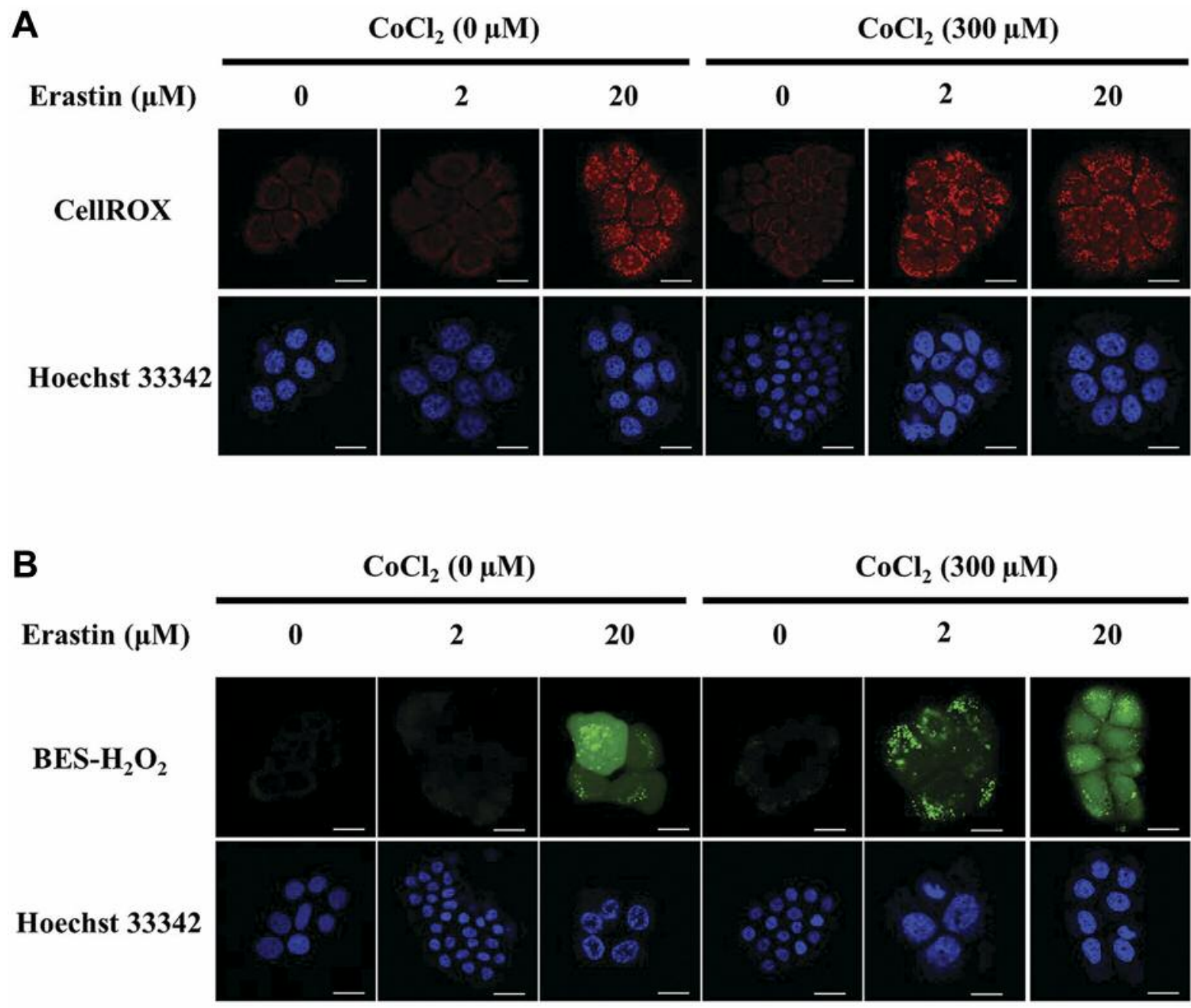

C

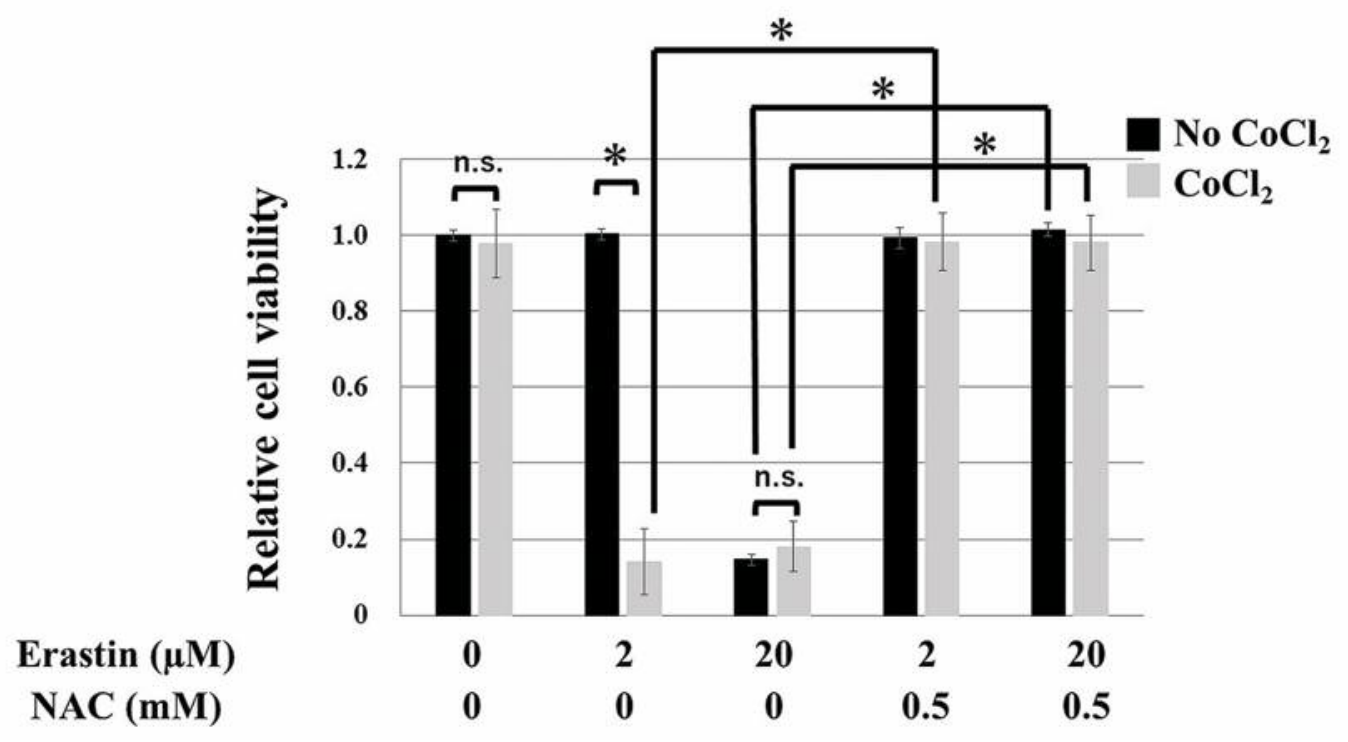


D

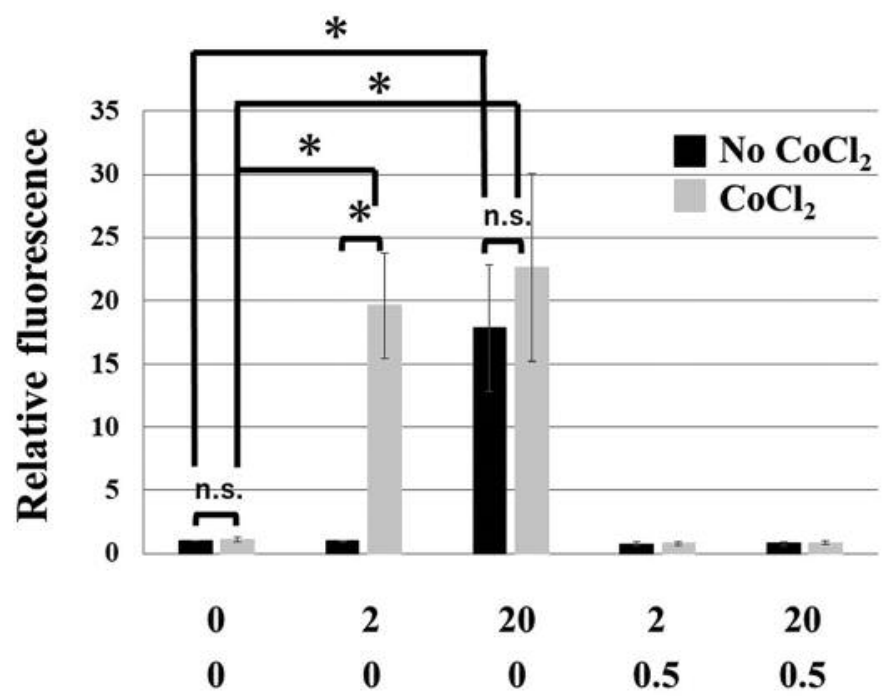

Figure 2. The role of reactive oxygen species in the effects induced by erastin under hypoxic conditions. BxPC-3 cells subjected to treatment with erastin with or without $300 \mu \mathrm{M} \mathrm{CoCl}{ }_{2}$ for $24 \mathrm{~h}$ were stained with Hoechst 33342 and $5 \mu M$ CellROX Green (A) or Hoechst 33342 and $5 \mu M$ BES$\mathrm{H}_{2} \mathrm{O}_{2}-\mathrm{Ac}(\mathrm{B})$. Bar $=10 \mu \mathrm{m} . \mathrm{BxPC}-3$ cells were also subjected to erastin treatment, with or without $300 \mu \mathrm{M} \mathrm{CoCl} \mathrm{C}_{2}$ in the presence of the scavenger $\mathrm{N}$-acetylcysteine $(\mathrm{NAC})$ and then assessed by $\mathrm{CCK}-8$ assay after $48 \mathrm{~h}(\mathrm{C})$ and by BES- $\mathrm{H}_{2} \mathrm{O}_{2}$-Ac fluorescence (D) after $24 \mathrm{~h} .{ }^{*}$ Significantly different at $p<0.05$; n.s.: not significantly different.

treatment with 2 and $20 \mu \mathrm{M}$ erastin (Figure 2A and B). Furthermore, upon treatment with NAC (25), which can eliminate a wide range of ROS, erastin-induced cytotoxicity under hypoxic conditions was inhibited, accompanied by a reduction in intracellular ROS levels (Figure $2 \mathrm{C}$ and D).

These results indicate that erastin-induced cytotoxicity depends mainly on the intracellular accumulation of ROS under hypoxic conditions.

Ferroptosis-independent cytotoxicity in a hypoxic environment. Erastin induces ferroptosis via lipid ROS accumulation. Therefore, ferrostatin- 1 , which selectively eliminates lipid ROS and inhibits ferroptosis, was used to investigate whether erastin-induced cytotoxicity involved ferroptosis. As previously reported (16), under normal conditions, ferrostatin-1 reversed cytotoxicity induced by $20 \mu \mathrm{M}$ erastin. However, under hypoxic conditions, ferrostatin-1 was not able to reverse cytotoxicity at the concentrations tested in our study (Figure $3 \mathrm{~A})$. Therefore necrostatin, an inhibitor of necroptosis (26), was used to investigate the involvement of a cell death type other than ferroptosis. Treatment with necrostatin also did not attenuate erastin-induced cell death (Figure 3B). These results indicate that erastin-induced cytotoxicity under hypoxic conditions does not involve ferroptosis or necroptosis, unlike that under normal conditions.

Apoptosis-dependent cytotoxicity under a hypoxic environment. We investigated the involvement of apoptosis in order to identify the specific mechanism of erastin-induced cytotoxicity in a hypoxic environment. We studied the cleavage of PARP, an indicator of apoptosis. The results strongly suggested that PARP cleavage was induced by erastin treatment under hypoxic conditions (Figure 4A). Consistent with the cell viability results, PARP cleavage was not restored by treatment with ferrostatin1 but was with NAC. These findings suggest that the cleavage of PARP induced by erastin in a hypoxic environment was not caused by lipid ROS but by other ROS (Figure 4B).

In addition, Z-VAD-FMK, an inhibitor of apoptosis (27), was used to further demonstrate that the cell death observed under hypoxic conditions was due to apoptosis. We found that the cytotoxicity of erastin under hypoxic conditions was markedly attenuated by Z-VAD-FMK (Figure 4C). Collectively, our results indicate that in a hypoxic environment, erastin-induced cytotoxicity is mediated by apoptosis.

\section{Discussion}

In the present study, we explored the potency of erastin as a novel anticancer compound targeting the hypoxic environment in pancreatic cancer and investigated the potential mechanisms underlying erastin-induced cytotoxicity. Using $\mathrm{CoCl}_{2}$ to mimic a hypoxic environment, we found that erastin exhibited cytotoxicity under a hypoxic environment. In-depth investigations need to be conducted in the future using other agents that mimic hypoxic conditions to better elucidate the roles and effects of erastin. 
A

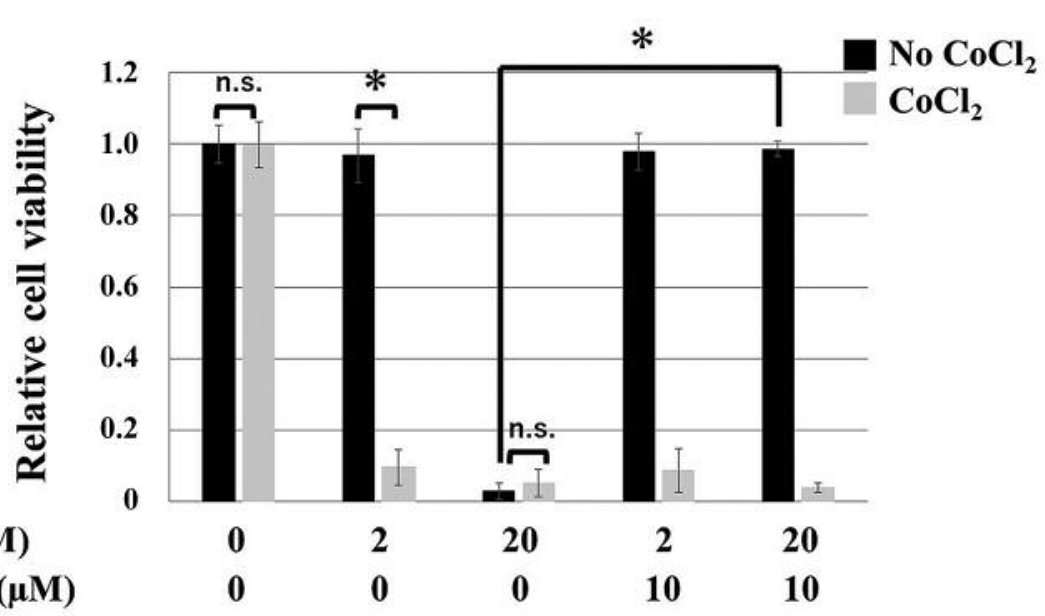

B

Erastin $(\mu \mathrm{M})$

Ferrostatin-1 $(\mu \mathrm{M})$

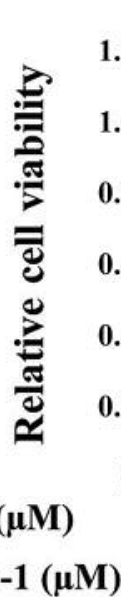

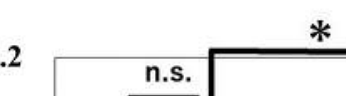

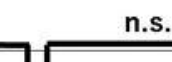

n.s.

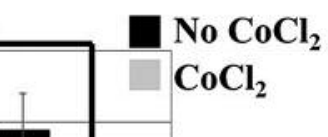

\section{Necrostatin-1 $(\mu \mathrm{M})$}

Erastin $(\mu \mathrm{M})$

Figure 3. Erastin-induced cytotoxicity was independent of ferroptosis and necroptosis. BxPC-3 cells were subjected to treatment for $48 \mathrm{~h}$ with erastin in the presence ferrostatin-1 (A) or necrostatin-1 (B) with or without $300 \mu M \mathrm{CoCl}_{2} .{ }^{*}$ Significantly different at p<0.05; n.s.: not significantly different.

In this study, the cytotoxicity induced by erastin was attenuated by NAC, which commonly eliminates a wide range of ROS in normal and hypoxic environments. This finding demonstrates the role of ROS in mediating erastininduced cell death. Erastin is a known inducer of ferroptosis, which is an iron-dependent mechanism of cell death mediated by lipid ROS, as first reported by Stockwell et al. in 2012 (22). Ferroptosis is recognised as a form of cell death distinct from apoptosis and necroptosis, the two wellestablished and classical forms of cell death (28). In the present study, cytotoxicity induced by erastin under normoxic conditions was attenuated by ferrostatin-1, which was consistent with the findings of another report (16). Therefore, the cytotoxicity induced by erastin in normoxic environments may be associated with ferroptosis. In addition, we revealed that erastin induces cytotoxicity even under hypoxic conditions, thereby fulfilling the aim of this study.
Surprisingly, erastin-induced cytotoxicity in a hypoxic environment was not attenuated by ferrostatin-1. Apparently, ferroptosis, which is mediated by lipid ROS, was not involved in erastin-induced cell death under hypoxic conditions. Furthermore, we found that erastin increased the level of ROS, except for lipid ROS, thereby inducing apoptosis. To the best of our knowledge, this is the first report showing that erastin can induce apoptosis in a hypoxic environment. We previously reported that strategies to increase the production of mitochondria-derived ROS and apoptosis rate may be effective in inducing cytotoxicity in hypoxic environments (11). It was also reported that erastin inhibits mitochondrial voltage-dependent anion channels leading to accumulation of $\operatorname{ROS}(29,30)$. In the future, the specific types of ROS that accumulate upon erastin treatment in hypoxic environments and the detailed mechanisms causing apoptosis should be investigated. 


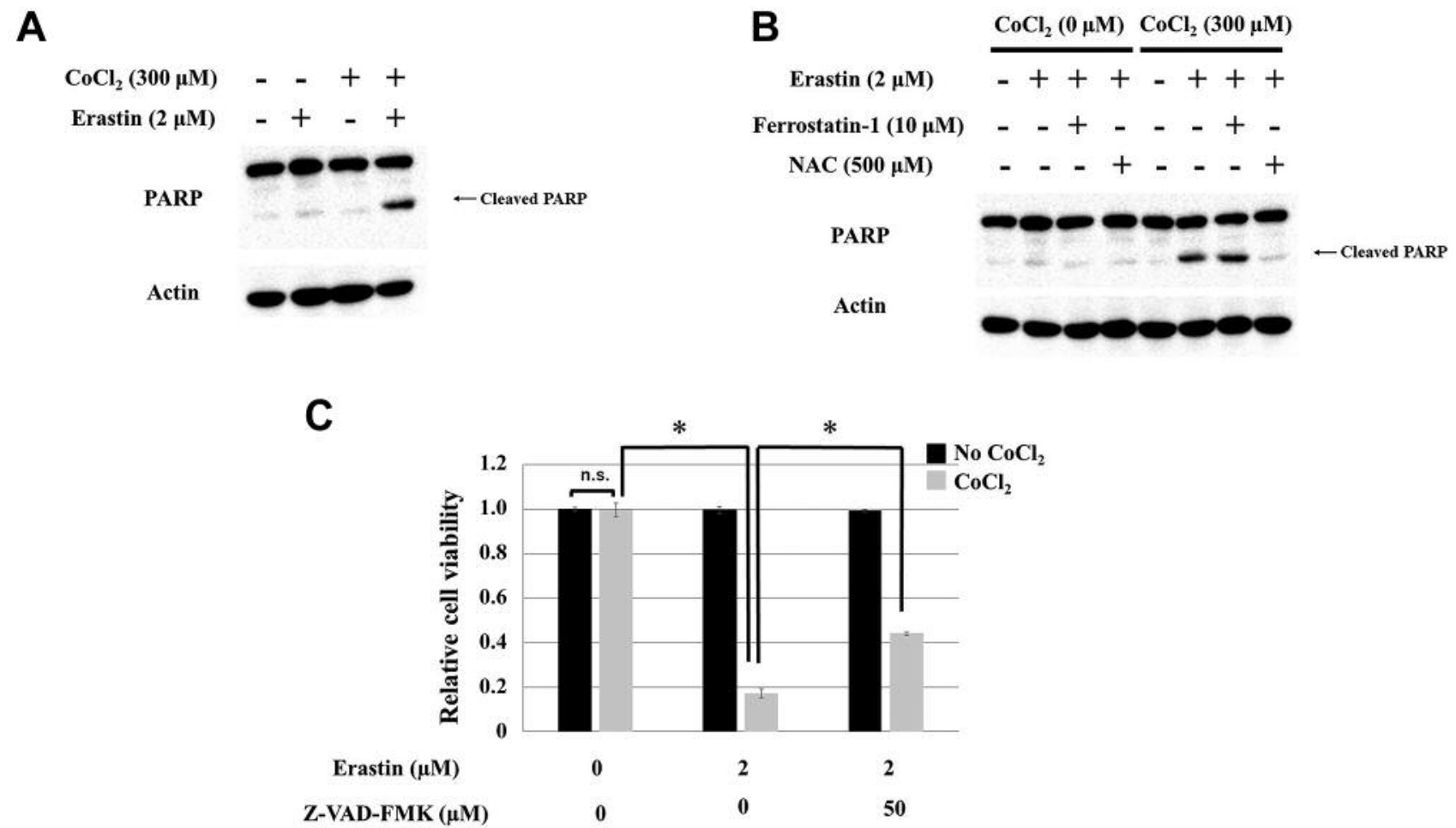

Figure 4. Erastin induced apoptosis under hypoxic conditions. A: The expression level of poly (ADP-ribose) polymerase (PARP) and actin in BxPC3 cells treated for $24 \mathrm{~h}$ with erastin in the absence or presence of $300 \mu \mathrm{M} \mathrm{CoCl}{ }_{2} . \mathrm{B}: \mathrm{BxPC}-3$ cells were treated with N-acetylcysteine (NAC) or ferrostatin-1 in the presence of erastin, with or without $300 \mu \mathrm{M} \mathrm{CoCl}$, for $24 \mathrm{~h}$, followed by the western blotting analysis of PARP and actin. C: $C C K-8$ assay was used to determine viability of BXPC-3 cells treated for $48 \mathrm{~h}$ with erastin with or without the apoptosis inhibitor Z-VAD FMK in the presence of $300 \mu \mathrm{M} \mathrm{CoCl} 2 .{ }^{*}$ Significantly different at $p<0.05$; n.s.: not significantly different.

Erastin has many advantages as a therapeutic agent. It was reported that cancer cells take up more iron than normal cells $(31,32)$. Ferroptosis is an iron-dependent form of cell death. Therefore, the use of erastin to induce ferroptosis can selectively induce cytotoxicity in cancer cells. In addition, it was revealed that erastin induced apoptosis and demonstrated cytotoxicity even in hypoxic environments, wherein chemotherapeutic agents were ineffective (7-10). Proper control of apoptosis is also important for the survival of normal cells. Therefore, it is of great concern that strategies to induce apoptosis in hypoxic environments may also impair the functioning of normal cells. However, unlike normal tissues, hypoxia is a characteristic feature of solid tumours $(33,34)$. Therefore, erastin not only enables the induction of ferroptosis in normally oxygenated areas and apoptosis in hypoxic areas but also has the potential to become a revolutionary therapeutic compound with fewer side-effects. Many animal studies have shown that erastin is effective in reducing tumours and does not induce serious side-effects (35-37). In addition, the presence of hypoxic areas in cancer tissues is a common phenomenon in many tumours besides pancreatic cancer (6). Thus, the cytocidal effect of erastin on cancer cells in a hypoxic environment in other organs should also be investigated.

In conclusion, we revealed that erastin exerts cytotoxic effects in a hypoxic environment, indicating its utility as a candidate compound against pancreatic cancer.

\section{Conflicts of Interest}

The Authors declare that they have no conflicts of interest.

\section{Authors' Contributions}

Conception and design of the study, S.O. and H.E. Collection and assembly of data S.O., H.E., Y.S., T.K., H.F., and M.T. Analysis and interpretation of data S.O. and H.E. Drafting of the article S.O. All Authors reviewed and approved the final version of the article.

\section{Acknowledgements}

Confocal microscopy analysis was performed by the Medical Science College Office of Tokai University. The Authors thank Yuko Okamoto and Akiko Sakuyama from the Department of Preventive Medicine, Tokai University School of Medicine, for their excellent 
secretarial support. The Authors would also like to thank Editage (www.editage.jp) for English language editing.

This study was supported in part by the 2017-2019 Research and Study Program of Tokai University Educational System General Research Organization (S.O.), 2021 Tokai University School of Medicine Research Aid (S.O.), and Grant-in-Aid for Scientific Research (21K15960 to S.O. and 21K19671 to H.E.) from the Ministry of Education, Culture, Sports, Science, and Technology, Japan.

\section{References}

1 Torre LA, Bray F, Siegel RL, Ferlay J, Lortet-Tieulent J and Jemal A: Global cancer statistics, 2012. CA Cancer J Clin 65(2): 87-108, 2015. PMID: 25651787. DOI: $10.3322 /$ caac.21262

2 Siegel RL, Miller KD and Jemal A: Cancer statistics, 2019. CA Cancer J Clin 69(1): 7-34, 2019. PMID: 30620402. DOI: $10.3322 /$ caac. 21551

3 Mizrahi JD, Surana R, Valle JW and Shroff RT: Pancreatic cancer. Lancet 395(10242): 2008-2020, 2020. PMID: 32593337. DOI: 10.1016/S0140-6736(20)30974-0

4 Brown JM and Wilson WR: Exploiting tumour hypoxia in cancer treatment. Nat Rev Cancer 4(6): 437-447, 2004. PMID: 15170446. DOI: $10.1038 /$ nrc1367

5 Eales KL, Hollinshead KE and Tennant DA: Hypoxia and metabolic adaptation of cancer cells. Oncogenesis 5: e190, 2016. PMID: 26807645. DOI: 10.1038/oncsis.2015.50

6 McKeown SR: Defining normoxia, physoxia and hypoxia in tumours-implications for treatment response. $\mathrm{Br} \mathrm{J}$ Radiol 87(1035): 20130676, 2014. PMID: 24588669. DOI: 10.1259/ bjr.20130676

7 Zhang X, Galardi E, Duquette M, Lawler J and Parangi S: Antiangiogenic treatment with three thrombospondin-1 type 1 repeats versus gemcitabine in an orthotopic human pancreatic cancer model. Clin Cancer Res 11(15): 5622-5630, 2005. PMID: 16061881. DOI: 10.1158/1078-0432.CCR-05-0459

8 Wang L, Xue M and Chung DC: c-Myc is regulated by HIF- $2 \alpha$ in chronic hypoxia and influences sensitivity to 5-FU in colon cancer. Oncotarget 7(48): 78910-78917, 2016. PMID: 27793037. DOI: $10.18632 /$ oncotarget.12911

9 Liang C, Dong Z, Cai X, Shen J, Xu Y, Zhang M, Li H, Yu W and Chen W: Hypoxia induces sorafenib resistance mediated by autophagy via activating FOXO3a in hepatocellular carcinoma. Cell Death Dis 11(11): 1017, 2020. PMID: 33250518. DOI: 10.1038/s41419-020-03233-y

10 Tang YA, Chen YF, Bao Y, Mahara S, Yatim SMJM, Oguz G, Lee PL, Feng M, Cai Y, Tan EY, Fong SS, Yang ZH, Lan P, Wu $\mathrm{XJ}$ and Yu Q: Hypoxic tumor microenvironment activates GLI2 via HIF- $1 \alpha$ and TGF- $\beta 2$ to promote chemoresistance in colorectal cancer. Proc Natl Acad Sci U.S.A. 115(26): E5990E5999, 2018. PMID: 29891662. DOI: 10.1073/pnas.1801348115

11 Owada S, Endo H, Shida Y, Okada C, Ito K, Nezu T and Tatemichi M: Autophagy-mediated adaptation of hepatocellular carcinoma cells to hypoxia-mimicking conditions constitutes an attractive therapeutic target. Oncol Rep 39(4): 1805-1812, 2018. PMID: 29484444. DOI: 10.3892/or.2018.6279

12 Owada S, Ito K, Endo H, Shida Y, Okada C, Nezu T and Tatemichi M: An adaptation system to avoid apoptosis via autophagy under hypoxic conditions in pancreatic cancer cells. Anticancer Res 37(9): 4927-4934, 2017. PMID: 28870914. DOI: 10.21873/anticanres. 11902
13 Owada S, Endo H, Okada C, Yoshida K, Shida Y and Tatemichi M: Setanaxib as a potent hypoxia-specific therapeutic agent against liver cancer. Anticancer Res 40(9): 5071-5079, 2020. PMID: 32878795. DOI: 10.21873/anticanres.14510

14 Gao H, Bai Y, Jia Y, Zhao Y, Kang R, Tang D and Dai E: Ferroptosis is a lysosomal cell death process. Biochem Biophys Res Commun 503(3): 1550-1556, 2018. PMID: 30031610. DOI: $10.1016 /$ j.bbrc.2018.07.078

15 Kwon OS, Kwon EJ, Kong HJ, Choi JY, Kim YJ, Lee EW, Kim W, Lee $\mathrm{H}$ and Cha HJ: Systematic identification of a nuclear receptor-enriched predictive signature for erastin-induced ferroptosis. Redox Biol 37: 101719, 2020. PMID: 32979793. DOI: 10.1016/j.redox.2020.101719

16 Badgley MA, Kremer DM, Maurer HC, DelGiorno KE, Lee HJ, Purohit V, Sagalovskiy IR, Ma A, Kapilian J, Firl CEM, Decker AR, Sastra SA, Palermo CF, Andrade LR, Sajjakulnukit P, Zhang L, Tolstyka ZP, Hirschhorn T, Lamb C, Liu T, Gu W, Seeley ES, Stone E, Georgiou G, Manor U, Iuga A, Wahl GM, Stockwell BR, Lyssiotis CA and Olive KP: Cysteine depletion induces pancreatic tumor ferroptosis in mice. Science 368(6486): 85-89, 2020. PMID: 32241947. DOI: 10.1126/ science.aaw9872

17 Daher B, Parks SK, Durivault J, Cormerais Y, Baidarjad H, Tambutte E, Pouysségur J and Vučetić M: Genetic ablation of the cystine transporter $\mathrm{xCT}$ in PDAC cells inhibits mTORC1, growth, survival, and tumor formation via nutrient and oxidative stresses. Cancer Res 79(15): 3877-3890, 2019. PMID: 31175120. DOI: 10.1158/0008-5472.CAN-18-3855

18 Owada S, Shimoda Y, Tsuchihara K and Esumi H: Critical role of $\mathrm{H} 2 \mathrm{O} 2$ generated by NOX4 during cellular response under glucose deprivation. PLoS One 8(3): e56628, 2013. PMID: 23555559. DOI: 10.1371 journal.pone.0056628

19 Endo H, Owada S, Inagaki Y, Shida Y and Tatemichi M: Metabolic reprogramming sustains cancer cell survival following extracellular matrix detachment. Redox Biol 36: 101643, 2020. PMID: 32863227. DOI: 10.1016/j.redox.2020.101643

20 Muñoz-Sánchez J and Chánez-Cárdenas ME: The use of cobalt chloride as a chemical hypoxia model. J Appl Toxicol 39(4): 556-570, 2019. PMID: 30484873. DOI: 10.1002/jat.3749

21 Dolma S, Lessnick SL, Hahn WC and Stockwell BR: Identification of genotype-selective antitumor agents using synthetic lethal chemical screening in engineered human tumor cells. Cancer Cell 3(3): 285-296, 2003. PMID: 12676586. DOI: 10.1016/s1535-6108(03)00050-3

22 Dixon SJ, Lemberg KM, Lamprecht MR, Skouta R, Zaitsev EM, Gleason CE, Patel DN, Bauer AJ, Cantley AM, Yang WS, Morrison B 3rd and Stockwell BR: Ferroptosis: an irondependent form of nonapoptotic cell death. Cell 149(5): 10601072, 2012. PMID: 22632970. DOI: 10.1016/j.cell.2012.03.042

23 Lozoya-Gloria E, Cornejo-Corona I, Thapa HR, Browne DR and Devarenne TP: ROS detection in Botryococcus braunii colonies with CellROX green reagent. Bio Protoc 7(16): e2508, 2017. PMID: 34541171. DOI: 10.21769/BioProtoc.2508

24 Maeda H, Fukuyasu Y, Yoshida S, Fukuda M, Saeki K, Matsuno $\mathrm{H}$, Yamauchi $\mathrm{Y}$, Yoshida $\mathrm{K}$, Hirata $\mathrm{K}$ and Miyamoto $\mathrm{K}$ : Fluorescent probes for hydrogen peroxide based on a nonoxidative mechanism. Angew Chem Int Ed Engl 43(18): 23892391, 2004. PMID: 15114569. DOI: 10.1002/anie.200452381

25 Šalamon Š, Kramar B, Marolt TP, Poljšak B and Milisav I: Medical and dietary uses of N-Acetylcysteine. Antioxidants 
(Basel) 8(5): 111, 2019. PMID: 31035402. DOI: 10.3390/ antiox 8050111

26 Degterev A, Hitomi J, Germscheid M, Ch'en IL, Korkina O, Teng X, Abbott D, Cuny GD, Yuan C, Wagner G, Hedrick SM, Gerber SA, Lugovskoy A and Yuan J: Identification of RIP1 kinase as a specific cellular target of necrostatins. Nat Chem Biol 4(5): 313-321, 2008. PMID: 18408713. DOI: 10.1038/ nchembio. 83

27 Slee EA, Zhu H, Chow SC, MacFarlane M, Nicholson DW and Cohen GM: Benzyloxycarbonyl-Val-Ala-Asp (OMe) fluoromethylketone (Z-VAD.FMK) inhibits apoptosis by blocking the processing of CPP32. Biochem J 315 (Pt 1): 21-24, 1996. PMID: 8670109 . DOI: $10.1042 / b j 3150021$

28 Galluzzi L, Vitale I, Aaronson SA, Abrams JM, Adam D, Agostinis P, Alnemri ES, Altucci L, Amelio I, Andrews DW, Annicchiarico-Petruzzelli M, Antonov AV, Arama E, Baehrecke EH, Barlev NA, Bazan NG, Bernassola F, Bertrand MJM, Bianchi $\mathrm{K}$, Blagosklonny MV, Blomgren K, Borner C, Boya P, Brenner C Campanella M, Candi E, Carmona-Gutierrez D, Cecconi F, Chan FK, Chandel NS, Cheng EH, Chipuk JE, Cidlowski JA, Ciechanover A, Cohen GM, Conrad M, Cubillos-Ruiz JR, Czabotar PE, D'Angiolella V, Dawson TM, Dawson VL, De Laurenzi V, De Maria R, Debatin KM, DeBerardinis RJ, Deshmukh M, Di Daniele N, Di Virgilio F, Dixit VM, Dixon SJ, Duckett CS, Dynlacht BD, El-Deiry WS, Elrod JW, Fimia GM, Fulda S, García-Sáez AJ, Garg AD, Garrido C, Gavathiotis E, Golstein P, Gottlieb E, Green DR, Greene LA, Gronemeyer H, Gross A, Hajnoczky G, Hardwick JM, Harris IS, Hengartner MO, Hetz C, Ichijo H, Jäättelä M, Joseph B, Jost PJ, Juin PP, Kaiser WJ, Karin M, Kaufmann T, Kepp O, Kimchi A, Kitsis RN, Klionsky DJ, Knight RA, Kumar S, Lee SW, Lemasters JJ, Levine B, Linkermann A, Lipton SA, Lockshin RA, López-Otín C, Lowe SW, Luedde T, Lugli E, MacFarlane M, Madeo F, Malewicz M, Malorni W, Manic G, Marine JC, Martin SJ, Martinou JC, Medema JP, Mehlen P, Meier P, Melino S, Miao EA, Molkentin JD, Moll UM, Muñoz-Pinedo C, Nagata S, Nuñez G, Oberst A, Oren M, Overholtzer M, Pagano M, Panaretakis T, Pasparakis M, Penninger JM, Pereira DM, Pervaiz S, Peter ME, Piacentini M, Pinton P, Prehn JHM, Puthalakath H, Rabinovich GA, Rehm M, Rizzuto R, Rodrigues CMP, Rubinsztein DC, Rudel T, Ryan KM, Sayan E, Scorrano L, Shao F, Shi Y, Silke J, Simon HU, Sistigu A, Stockwell BR, Strasser A, Szabadkai G, Tait SWG, Tang D, Tavernarakis N, Thorburn A, Tsujimoto Y, Turk B, Vanden Berghe T, Vandenabeele P, Vander Heiden MG, Villunger A, Virgin HW, Vousden KH, Vucic D, Wagner EF, Walczak H, Wallach D, Wang Y, Wells JA, Wood W, Yuan J, Zakeri Z, Zhivotovsky B, Zitvogel L, Melino G and Kroemer G: Molecular mechanisms of cell death: recommendations of the Nomenclature Committee on Cell Death 2018. Cell Death Differ 25(3): 486-541, 2018. PMID: 29362479. DOI: $10.1038 / \mathrm{s} 41418-017-0012-4$
29 Huo H, Zhou Z, Qin J, Liu W, Wang B and Gu Y: Erastin disrupts mitochondrial permeability transition pore (mPTP) and induces apoptotic death of colorectal cancer cells. PLoS One 11(5): e0154605, 2016. PMID: 27171435. DOI: 10.1371/ journal.pone.0154605

30 Sun Y, Deng R and Zhang C: Erastin induces apoptotic and ferroptotic cell death by inducing ROS accumulation by causing mitochondrial dysfunction in gastric cancer cell HGC-27. Mol Med Rep 22(4): 2826-2832, 2020. PMID: 32945484. DOI: $10.3892 / \mathrm{mmr} .2020 .11376$

31 Zhang $\mathrm{C}$ and Zhang F: Iron homeostasis and tumorigenesis: molecular mechanisms and therapeutic opportunities. Protein Cell 6(2): 88-100, 2015. PMID: 25476483. DOI: 10.1007/ s13238-014-0119-Z

32 Zhou L, Zhao B, Zhang L, Wang S, Dong D, Lv H and Shang $\mathrm{P}$ : Alterations in cellular iron metabolism provide more therapeutic opportunities for cancer. Int J Mol Sci 19(5): 1545, 2018. PMID: 29789480. DOI: 10.3390/ijms19051545

33 Jain RK: Normalization of tumor vasculature: an emerging concept in antiangiogenic therapy. Science 307(5706): 58-62, 2005. PMID: 15637262. DOI: 10.1126/science.1104819

34 Ager A, Watson HA, Wehenkel SC and Mohammed RN: Homing to solid cancers: a vascular checkpoint in adoptive cell therapy using CAR T-cells. Biochem Soc Trans 44(2): 377-385, 2016. PMID: 27068943. DOI: 10.1042/BST20150254

35 Yang WS, SriRamaratnam R, Welsch ME, Shimada K, Skouta R, Viswanathan VS, Cheah JH, Clemons PA, Shamji AF, Clish CB, Brown LM, Girotti AW, Cornish VW, Schreiber SL and Stockwell BR: Regulation of ferroptotic cancer cell death by GPX4. Cell 156(1-2): 317-331, 2014. PMID: 24439385. DOI: 10.1016/j.cell.2013.12.010

36 Zhang Y, Tan H, Daniels JD, Zandkarimi F, Liu H, Brown LM, Uchida K, O'Connor OA and Stockwell BR: Imidazole ketone erastin induces ferroptosis and slows tumor growth in a mouse lymphoma model. Cell Chem Biol 26(5): 623-633.e9, 2019. PMID: 30799221. DOI: 10.1016/j.chembiol.2019.01.008

37 Li Y, Wang X, Yan J, Liu Y, Yang R, Pan D, Wang L, Xu Y, Li $\mathrm{X}$ and Yang $\mathrm{M}$ : Nanoparticle ferritin-bound erastin and rapamycin: a nanodrug combining autophagy and ferroptosis for anticancer therapy. Biomater Sci 7(9): 3779-3787, 2019. PMID: 31211307. DOI: $10.1039 / \mathrm{c} 9 \mathrm{bm} 00653 \mathrm{~b}$
Received August 20, 2021

Revised September 17, 2021 Accepted September 21, 2021 